\title{
Effect of Intraventricular Administration of Vasoactive Intestinal Polypeptide on Body Temperature in the Rat
}

\author{
Shinji IтоH and Ryoji Hirota \\ Shionogi Research Laboratories, Fukushima-ku, Osaka, 553 Japan
}

\begin{abstract}
Summary Intracerebroventricular injection of vasoactive intestinal polypeptide (VIP) into rat caused a temporary elevation of body temperature followed by a decrease to below the control level. Hypothermia induced by cholecystokinin octapeptide was abolished by simultaneous administration of VIP. Hypothermia following pentobarbital administration was reduced by successive injections of VIP. The results suggest that multiple interactions of neuropeptides are involved in central thermoregulation.

Key Words: vasoactive intestinal polypeptide, body temperature, cholecystokinin, pentobarbital.
\end{abstract}

High concentrations of vasoactive intestinal polypeptide (VIP) exist in both the gut and the brain. Like most other neuropeptides, VIP is preferentially contained in the synaptosomal fraction and released in vitro by depolarization (GIACHETtr et al., 1977; EMSON et al., 1978; BESSON et al., 1979). These findings suggest that VIP may act as a neurotransmitter or a neuromodulator. With regard to the thermoregulatory action of VIP, CLARK et al. (1978) briefly reported that intracerebroventricular (i.c.v.) injection of VIP produced hyperthermia in the cat. Although several other neuropeptides have been shown to affect body temperature, the finding that VIP produces hyperthermia suggests that it may also play a role in central thermoregulation. Thus the present study was undertaken to ascertain this effect of VIP in the rat and to observe its action on drug-induced hypothermia.

Male Wistar rats, weighing approximately $250 \mathrm{~g}$, were housed at a constant temperature of $25^{\circ} \mathrm{C}$ under controlled illumination (lights on from 07:00 to 19:00 hr) with free access to rat biscuits (Oriental Yeast Co.) and water. The method of i.c.v. injection was described in detail in our previous paper (Ітон et al., 1979). Drugs used in the present experiments were VIP (Penninsula Labs.), C-terminal octapeptide of cholecystokinin (CCK-8, Calbiochem.) and sodium pentobarbital (Pitman-Moore). VIP and CCK-8 were dissolved in physiological saline solution

Received for publication January 27, 1982

伊藤畺次, 広田良二 
to graded concentrations just prior to use and injected i.c.v. in a volume of $5 \mu 1$. Body temperature was measured with the room temperature at $25^{\circ} \mathrm{C}$ using a thermistor with the probe inserted into the colon at a depth of $5 \mathrm{~cm}$ from the anus. The experiments were always started at around 10:00 a.m. and before each experiment, the colonic temperature was checked for stability for at least $30 \mathrm{~min}$, the test sample then being injected. Measurements were done every $10 \mathrm{~min}$ for 60 or $120 \mathrm{~min}$ and the data were analyzed by Student's $t$-test.

At the start of experiments the average colonic temperature was $38.4 \pm 0.04^{\circ} \mathrm{C}$ (S.E.M.). As shown in Fig. 1, i.c.v. injection of VIP in doses of 1 and $10 \mu \mathrm{g}$ caused significant elevation of the colonic temperature $30 \mathrm{~min}$ after the injection, although it thereafter decreased to below the control level. As CCK- 8 has been found to cause hypothermia (KATSUURA and ITOH, 1981), the effect of VIP on CCK-8-induced hypothermia was examined. Combined i.c.v. injection of CCK-8 (800 ng) and VIP $(0.1-10 \mu \mathrm{g})$ showed that VIP had a suppressive influence on CCK-8-induced hypothermia (Fig. 2a). Although $0.1 \mu \mathrm{g}$ of VIP was not very effective, when 1 or $10 \mu \mathrm{g}$ of VIP was administered together with CCK-8, no significant changes in the colonic temperature were seen as compared with the levels of the saline control group.

In another series of experiments, sodium pentobarbital was first injected intraperitoneally in a dose of $50 \mathrm{mg} / \mathrm{kg}$. Ten min later the colonic temperature decreased $0.4 \pm 0.06^{\circ} \mathrm{C}$; at this time VIP was administered i.c.v. and changes in the temperature were observed. As shown in Fig. 2b, pentobarbital produced marked long-lasting hypothermia. When VIP was given in a dose of $0.1 \mu \mathrm{g}$ the degree of the hypothermia decreased, but the difference between the temperature after this dose of VIP and that of saline control was not significant. However, when the dose of VIP was increased to 1 or $10 \mu \mathrm{g}$, the fall in colonic temperature induced

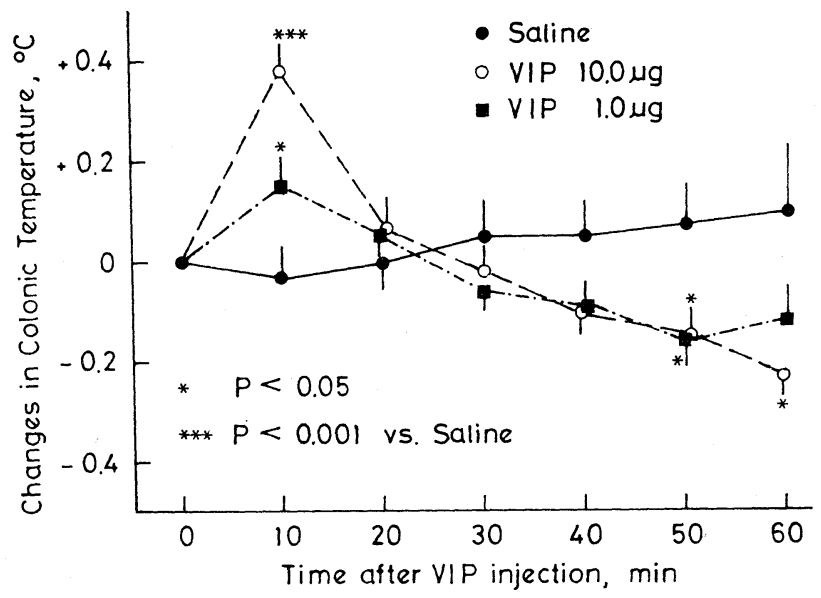

Fig. 1. Changes in colonic temperature following i.c.v. injection of VIP. The number of rats is 10 in every experiment. Vertical lines indicate standard errors. 

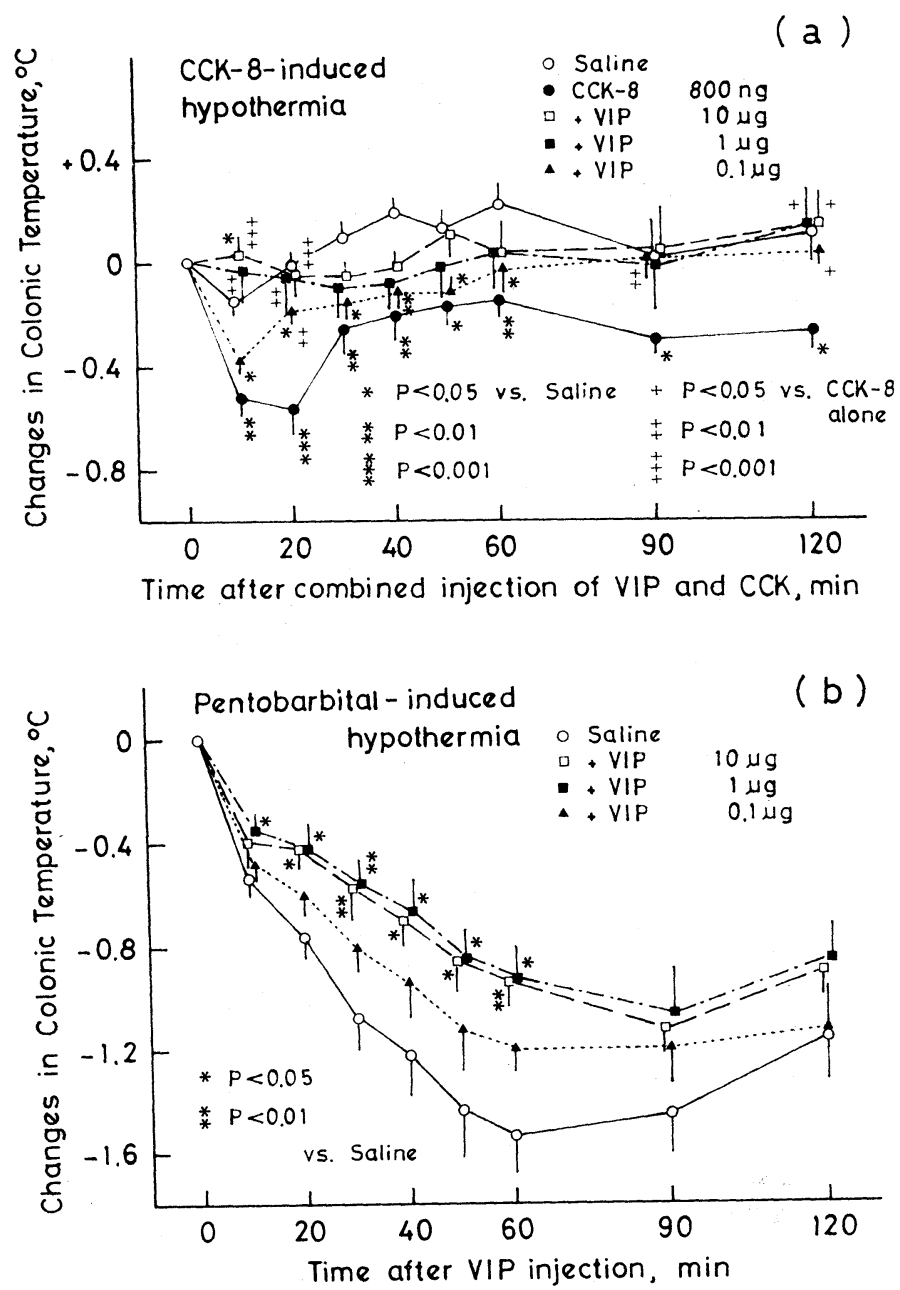

Fig. 2. Effect of i.c.v. injection of VIP on hypothermia induced by i.c.v. administration of $800 \mathrm{ng}$ of CCK-8 (a) and intraperitoneal injection of $50 \mathrm{mg} / \mathrm{kg}$ of pentobarbital (b). The number of rats is 10 in every experiment. Vertical lines indicate standard errors.

by pentobarbital was apparently reduced.

As mentioned above, CLARK et al. (1978) reported a hyperthermic effect of VIP in the cat. According to their observation, the hyperthermic response lasted for about $30 \mathrm{~min}$. A similar effect of VIP was also found in rats in the present study, but the hyperthermia was of rather short duration and 50 to $60 \mathrm{~min}$ after the injection, the colonic temperature was lower than the level of the saline control. This delayed decrease in body temperature may have been caused by the compensative release of some hypothermic neuropeptides, such as TRH metab- 
olite, cyclo (His-Pro), neurotensin, bombesin and angiotensin II, in response to VIP-induced hyperthermia. Another possibility is that the hypothermia is due to increased heat loss induced by the vasodilating action of VIP.

According to WeI et al. (1980), VIP has a strong vasodilator effect on cat pial arterioles, and this effect is assumed to be mediated by prostaglandins. Since the hyperthermic action of prostaglandins has been extensively studied by a number of investigators, VIP-induced elevation of body temperature might be due to its facilitation of prostaglandin production. However, no confirmative evidence for this mode of action is available at present. EPELBAUM et al. (1979) reported that VIP induced dose-dependent inhibition of release of somatostatin from mediobasal hypothalamic slices of the rat. Somatostatin acts in the brain to reverse chemically induced hypothermia and produce hyperthermia. Moreover, somatostatin was shown to be more potent and longer acting than prostaglandin $E_{2}$ in producing hyperthermia (BROWN et al., 1981). On the other hand, a controversial report was presented by CHANDRA et al. (1981) who showed that i.c.v. administration of somatostatin produced dose-dependent hypothermia at low and moderate ambient temperatures, but hyperthermia at a high ambient temperature. In order to clarify the complicated processes of the central thermoregulatory mechanisms in relation to various neuropeptides, further investigations must be conducted under different experimental conditions. Interactions of neuropeptides would be the most important issue in such studies.

\section{REFERENCES}

Besson, J., Rotsztejn, W. H., Laburthe, M., Epelbaum, J., Beaudet, A., Kordon, C., and Rosselin, G. (1979) Vasoactive intestinal peptide (VIP): Brain distribution, subcellular localization and effect of deafferentation of the hypothalamus in male rats. Brain Res., 165: 79-85.

Brown, M., LiNG, N., and RIVIER, J. (1981) Somatostatin-28, somatostatin-14 and somatostatin analogs: Effect on thermoregulation. Brain Res., 214: 127-135.

Chandra, A., Chou, H. C., Chang, C., and Lin, N. T. (1981) Effects of intraventricular administration of neurotensin and somatostatin on thermoregulation in the rat. Neuropharmacology, 20: 715-718.

ClARK, W. G., LiPTON, J. M., and SAID, S. I. (1978) Hyperthermic response to vasoactive intestinal polypeptide (VIP) injected into the third ventricle of cats. Neuropharmacology, 17: 883-885.

Emson, P. C., Fahrenkrug, J., Schaffalitzky de Muckadell, O. B., Jessell, T. M., and IVERSEN, L. L. (1978) Vasoactive intestinal polypeptide (VIP): Vesicular localization and potassium-evoked release from rat hypothalamus. Brain Res., 143: 174-178.

Epelbaum, J., Tapia-Arancibia, L., Besson, J., Rotsztejn, W. H., and Kordon, C. (1979) Vasoactive intestinal peptide inhibits release of somatostatin from hypothalamus in vitro. Eur. J. Pharmacol., 58: 493-495.

Giachetti, A., Said, S. I., Reynolds, R. C., and Koniges, F. C. (1977) Vasoactive intestinal polypeptide in brain: Localization in and from isolated nerve terminals. Proc. Natl. Acad. Sci. U.S.A., 74: 3424-3428.

Itoh, S., Hirota, R., Katsuura, G., and Odaguchi, K. (1979) Adrenocortical stimulation by 
a cholecystokinin preparation in the rat. Life Sci., 25: 1725-1730.

KatsuURA, G. and Iтон, S. (1981) Effect of cholecystokinin octapeptide on body temperature in the rat. Jpn. J. Physiol., 31: 849-858.

WeI, E. P., Kontos, H. A., and SAID, S. I. (1980) Mechanism of vasoactive intestinal polypeptide on cerebral arterioles. Am. J. Physiol., 239: H765-768. 